\title{
Predictors of No-reflow Phenomenon in ST-elevation Myocardial Infarction in Patients Undergoing Primary Percutaneous Coronary Intervention
}

\author{
Khaled Mohamed Said Othman*, Hesham Samir Abdelaziz AbdelKawy Aggour, \\ Samir Saleh Wafa, Mohamed El Sayed Zahran
}

Cardiology Department, Ain Shams University, Cairo, Egypt

Email address:

kh_m_saeed@yahoo.com (K. M. S. Othman)

${ }^{*}$ Corresponding author

To cite this article:

Khaled Mohamed Said Othman, Hesham Samir Abdelaziz AbdelKawy Aggour, Samir Saleh Wafa, Mohamed El Sayed Zahran. Predictors of No-reflow Phenomenon in ST-elevation Myocardial Infarction in Patients Undergoing Primary Percutaneous Coronary Interventiona. Cardiology and Cardiovascular Research. Vol. 3, No. 2, 2019, pp. 22-26. doi: 10.11648/j.ccr.20190302.11

Received: March 30, 2019; Accepted: May 7, 2019; Published: June 11, 2019

\begin{abstract}
Background Primary Percutaneous coronary intervention (PPCI) is an established mainstay in treatment of patients presenting with acute ST elevation myocardial infarction (STEMI). However, successful revascularization of the culprit coronary vessel does not always mean ideal myocardial reperfusion in a portion of patients, mainly because of the noreflow phenomenon. Myocardial no-reflow is associated with worse contractile dysfunction and higher incidence of complications and is an independent predictor of death and myocardial infarction after PPCI. Objective: To study the relationship between admissions CRP, Albumin, CRP/Albumin ratio, Monocyte, HDL, and Monocyte/HDL ratio, in patients presenting with acute STEMI and angiographic no-reflow after PPCI. Material and Methods: From October 2018 to February 2019, of the 1500 patients who presented with STEMI for PPCI to any of the Ain Shams University Hospitals' cath labs, we enrolled 150 consecutive patients who had post revascularization angiographic no-reflow. They were allocated to group A. we allocated 150 age, gender, and baseline characteristics matched STEMI patients who had TIMI III flow post revascularization to group B. this was set as the control group. Results: The study population was divided into 2 groups: no-reflow "A" $(\mathrm{n}=150)$ and reflow "B" $(\mathrm{n}=150)$ groups. CRP and Monocytes were significantly higher in the no-reflow group; Albumin and HDL were significantly lower in the no-reflow group. The novel indices, CRP/Albumin ratio (CAR) and Monocytes/HDL ratio (MHR) were both significantly higher in the no-reflow group ( $\mathrm{p}$ value $=0.000$ ) for both. The tow indices were found to be independent predictors of no-reflow development. Conclusion: Our results suggested that CAR and MHR on admission before PPCI though cheap, and easily measurable laboratory tools, have a significant predictive value with an odds ratio of 0.182 with a $\mathrm{p}$ value $=0.000$ and 0.321 with a $\mathrm{p}$ value $=0.002$ respectively. They could help to risk stratify STEMI patients who might suffer from no-reflow phenomenon after PPCI.
\end{abstract}

Keywords: No-reflow, CRP/Albumin Ratio, Monocytes/HDL Ratio

\section{Introduction}

Acute myocardial infarction (MI) is the leading cause of death worldwide. It has been widely accepted that it is due to the insufficient blood supply to the cardiac tissue. Early revascularization with primary percutaneous coronary intervention (PPCI) after acute ST elevation myocardial infarction (STEMI) is associated with high success rates for
Thrombolysis in Myocardial Infarction (TIMI) III flow attainment and improved prognosis [1]. However, successful revascularization of the epicardial coronary artery does not always mean optimal myocardial reperfusion in a sizeable portion of patients, mostly because of no-reflow phenomenon.

The hallmarks of the 'no-reflow' phenomenon are myocyte swelling, endothelial cell swelling with luminal protrusions, and intravascular red blood cell aggregates [2]. Later findings 
included presence of capillary leukocyte plugging [3] and to a lesser extent, platelet and fibrin accumulation [4, 5]. Myocardial damage always precedes the microvascular abnormalities in the presence of total coronary occlusion caused by a coronary thrombus and not vice versa [3].

No-reflow is a multifactorial phenomenon and five mechanisms have been recognized [6]: (A) pre-existing microvascular dysfunction, (B) distal micro-thromboembolization, (C) ischemic injury, (D) reperfusion injury, and (E) individual susceptibility. All these factors are interrelated in a complex manner.

Recently, clinical researches had focused on the predictive values of blood cell-related biomarkers on admission and their usefulness in modifying the clinical approach of noreflow phenomenon in patients with acute myocardial infarction (AMI). Recent investigations have suggested that CRP, monocytes, albumin, and HDL may be involved in the pathogenesis of coronary artery disease $[7,8]$. The present study aimed to investigate the relationship between on admission CRP, albumin, monocyte count, and HDL; and post-intervention no-reflow in patients treated by PPCI, because it would be valuable to be able to predict and risk stratify STEMI patients who might suffer from no-reflow phenomenon after PPCI.

\section{Aim of Study}

To study the relationship between admissions CRP, Albumin, CRP/Albumin ratio, Monocyte, HDL, and Monocyte/HDL ratio, in patients presenting with acute STEMI and angiographic no-reflow after PPCI.

\section{Patients and Methods}

This was an observational case control study conducted in the coronary care units in Ain Shams University Hospitals.

From October 2018 to February 2019, of the 1500 patients who presented with STEMI for PPCI to any of the Ain Shams University Hospitals' cath labs, we enrolled 150 consecutive patients who had post revascularization angiographic no-reflow; They were allocated to group "A". We then allocated 150 age, gender, and baseline characteristics matched STEMI patients who had TIMI III flow post revascularization to group "B"; This was set as the control group. We excluded patients with late presentation (chest pain onset $>48 \mathrm{hrs}$ ), patients who received thrombolytic therapy, and patients with chronic inflammatory, hematological, or Chronic Kidney disease (CKD) stage 4/5.

STEMI was defined as: typical chest pain $>30 \mathrm{~min}$ with ST elevation $>1 \mathrm{~mm}$ in at least two consecutive leads on the electrocardiogram or new onset left bundle branch block, and more than two-fold increase in serum cardiac biomarkers [9]. The institutional review board approved this study and all patients provided written informed consent to participate.

After history, clinical examination, and 12 lead surface ECG; STEMI patients who met inclusion criteria were screened for the admission results of: 1) CRP $(n<6), 2)$ serum albumin $(\mathrm{n}=3.4-4.8 \mathrm{~g} / \mathrm{dL}), 3)$ monocyte count $(\mathrm{n}=0.20-1.00$ $\left.\left.10^{\wedge} 3 / \mathrm{uL}\right), 4\right)$ HDL $(\mathrm{n}>40 \mathrm{mg} / \mathrm{dL}$ ), and 5) eGFR (All samples were withdrawn on admission in the emergency room prior to the administration of antiplatelets). Study blind expert operators assessed Echocardiography data (on admission and pre-discharge), measuring EF in the parasternal long axis, and apical 4 chamber views, using 2D eyeballing. We graded the Angiographic flow in the culprit vessel post revascularization using TIMI flow score as follows: TIMI 0: No perfusion, TIMI 1: penetration with no perfusion, TIMI 2: partial perfusion, TIMI 3: complete perfusion [10].

Primary PCI was performed after patients were loaded with dual anti-platelets (DAPT) using the standard procedural protocol for PPCI as approved by the Cardiology Department Ain Shams University. No-reflow after PPCI was defined as TIMI flow grade 2 or less after stent deployment in the culprit lesion despite the absence of angiographic residual stenosis, spasm, dissection, or thrombosis. Normalreflow was defined as post-revascularization TIMI grade III flow.

Statistical analysis: Data were collected, coded, revised and entered to the Statistical Package for Social Science (IBM SPSS) version 20. The data were presented in the form of numbers and percentages for the qualitative data; mean, standard deviations, and ranges for the quantitative data with parametric distribution. Chi-square test was used in the comparison between two groups with qualitative data. The comparison between two groups with quantitative data and parametric distribution were done by using Independent $t$ test. Multi-variate logistic regression analysis was used to assess predictors of no reflow among the studied patients. The confidence interval was set to $95 \%$ and the margin of error accepted was set to $5 \%$. So, the p-value was considered significant as the following: $p \geq 0.05$ : Non-significant (NS), $\mathrm{p}<0.05$ : Significant $(\mathrm{S}), \mathrm{p}<0.01$ : Highly significant (HS)

\section{Results}

This study recruited 300 patients, and according to the patients' PPCI outcome, patients were divided into two groups; the first group was the patients who suffered from no-reflow "A". The second group included patients with normal reflow outcome "B". The two groups were matched regarding age, gender, hypertension, diabetes mellitus, previous history of IHD, smoking, and family history of CAD with $\mathrm{p}$ value $>0.05$, table 1 .

Table 2, depicts the relationship between the laboratory parameters from blood samples withdrawn before primary PCI and the TIMI flow outcome of the primary intervention. There was no difference between the two groups regarding eGFR [75.08 vs $75.56 \mathrm{~mL} / \mathrm{min}$ per $1.73 \mathrm{~m}^{2}, \mathrm{p}=0.893$ ]. However, all other parameters showed significant statistical differences between the 2 groups. CRP was significantly higher in the no-reflow group showing a median (IQR) of 27.50 against 6.00 in the reflow group $(P$ value $=0.000)$. 
Albumin was lower in the no-reflow group with a mean of $3.58 \mathrm{~g} / \mathrm{dL}$ in contrast to $4.00 \mathrm{~g} / \mathrm{dL}$ in the reflow group (P value $=0.000)$. Other acute phase reactant (Monocytes and HDL) also showed highly significant difference between the
2 groups. The novel indices, $\mathrm{CRP} /$ Albumin ratio (CAR) and Monocytes/HDL (MHR) were both significantly higher in the no-reflow group in contrast to the reflow group, $(\mathrm{P}$ value $=0.000$ ) for both. Figure 1 .

Table 1. Comparison between group A and group B regarding age, gender, and CAD risk factors.

\begin{tabular}{|c|c|c|c|c|c|c|c|c|}
\hline & & \multicolumn{2}{|c|}{ No-Reflow group } & \multicolumn{2}{|c|}{ Reflow group } & \multirow{2}{*}{ Test value* } & \multirow{2}{*}{ P-value } & \multirow{2}{*}{ Sig. } \\
\hline & & No. & $\%$ & No. & $\%$ & & & \\
\hline \multirow{2}{*}{ Age } & Mean \pm SD & $64.10 \pm 10.60$ & & $61.50 \pm 8.66$ & & \multirow{2}{*}{$1.343 \bullet$} & \multirow{2}{*}{0.182} & \multirow{2}{*}{ NS } \\
\hline & Range & $31-82$ & & $37-84$ & & & & \\
\hline \multirow{2}{*}{ Gender } & Female & 30 & $(20.0 \%)$ & 39 & $(26.0 \%)$ & \multirow{2}{*}{$0.508 *$} & \multirow{2}{*}{0.476} & \multirow{2}{*}{ NS } \\
\hline & Male & 120 & $(80.0 \%)$ & 111 & $(74.0 \%)$ & & & \\
\hline \multirow{2}{*}{$\mathrm{DM}$} & No & 84 & $56.0 \%$ & 54 & $48.0 \%$ & \multirow{2}{*}{4.026} & \multirow{2}{*}{0.145} & \multirow{2}{*}{ NS } \\
\hline & Yes & 66 & $44.0 \%$ & 96 & $52.0 \%$ & & & \\
\hline \multirow{2}{*}{ HTN } & No & 66 & $44.0 \%$ & 60 & $40.0 \%$ & \multirow{2}{*}{0.164} & \multirow{2}{*}{0.685} & \multirow{2}{*}{ NS } \\
\hline & Yes & 84 & $56.0 \%$ & 90 & $60.0 \%$ & & & \\
\hline \multirow{2}{*}{ Smoking } & No & 54 & $36.0 \%$ & 75 & $50.0 \%$ & \multirow{2}{*}{1.999} & \multirow{2}{*}{0.157} & \multirow{2}{*}{ NS } \\
\hline & Yes & 96 & $64.0 \%$ & 75 & $50.0 \%$ & & & \\
\hline \multirow{2}{*}{ History of IHD } & No & 132 & $88.0 \%$ & 132 & $88.0 \%$ & \multirow{2}{*}{0.000} & \multirow{2}{*}{1.000} & \multirow{2}{*}{ NS } \\
\hline & Yes & 18 & $12.0 \%$ & 18 & $12.0 \%$ & & & \\
\hline \multirow{2}{*}{ FH } & No & 141 & $94.0 \%$ & 141 & $94.0 \%$ & \multirow{2}{*}{0.000} & \multirow{2}{*}{1.000} & \multirow{2}{*}{ NS } \\
\hline & Yes & 9 & $6.0 \%$ & 9 & $6.0 \%$ & & & \\
\hline
\end{tabular}

DM: Diabetes Mellitus, HTN: Hypertension, FH: Family history of IHD, P-value $\geq 0.05$ : Non significant (NS); P-value $<0.05$ : Significant (S); P-value $<0.01$ : highly significant (HS), *: Chi-square test, $\bullet$ Independent t-test; + : Mann Whitney test.

Table 2. Comparison between group A and group B as regards to Laboratory parameters and indices.

\begin{tabular}{|c|c|c|c|c|c|c|}
\hline & & \multirow{2}{*}{$\begin{array}{l}\text { No Reflow group } \\
\text { No. }=\mathbf{5 0} \\
\end{array}$} & \multirow{2}{*}{$\begin{array}{l}\text { Reflow group } \\
\text { No. }=\mathbf{5 0} \\
\end{array}$} & \multirow{2}{*}{ Test value } & \multirow{2}{*}{ P-value } & \multirow{2}{*}{ Sig. } \\
\hline & & & & & & \\
\hline eGFR & $\begin{array}{l}\text { Mean } \pm \text { SD } \\
\text { Range }\end{array}$ & $\begin{array}{l}75.08 \pm 19.59 \\
30-110\end{array}$ & $\begin{array}{l}75.56 \pm 15.57 \\
45-120\end{array}$ & $-0.135 \bullet$ & 0.893 & NS \\
\hline CRP & $\begin{array}{l}\text { Median (IQR) } \\
\text { Range }\end{array}$ & $\begin{array}{l}27.50(19-53) \\
8-185\end{array}$ & $\begin{array}{l}6.00(6-8) \\
6-18\end{array}$ & $-8.312 \neq$ & 0.000 & HS \\
\hline Albumin & $\begin{array}{l}\text { Mean } \pm \text { SD } \\
\text { Range }\end{array}$ & $\begin{array}{l}3.58 \pm 0.38 \\
2.8-4.4\end{array}$ & $\begin{array}{l}4.00 \pm 0.35 \\
3.4-4.6\end{array}$ & $-5.764 \bullet$ & 0.000 & HS \\
\hline CRP / Albumin & $\begin{array}{l}\text { Median (IQR) } \\
\text { Range }\end{array}$ & $\begin{array}{l}7.17(5.58-16.18) \\
2.16-44.05\end{array}$ & $\begin{array}{l}1.62(1.46-2) \\
1.3-4.74\end{array}$ & $-8.303 \neq$ & 0.000 & HS \\
\hline Monocytes & $\begin{array}{l}\text { Mean } \pm \text { SD } \\
\text { Range }\end{array}$ & $\begin{array}{l}2.44 \pm 0.71 \\
1.39-3.7\end{array}$ & $\begin{array}{l}0.48 \pm 0.16 \\
0.2-1.25\end{array}$ & $19.894 \bullet$ & 0.000 & HS \\
\hline HDL & $\begin{array}{l}\text { Mean } \pm \text { SD } \\
\text { Range }\end{array}$ & $\begin{array}{l}35.32 \pm 5.95 \\
27-51\end{array}$ & $\begin{array}{l}39.28 \pm 7.76 \\
28-65\end{array}$ & $-2.864 \bullet$ & 0.005 & HS \\
\hline Monocytes / HDL & $\begin{array}{l}\text { Mean } \pm \mathrm{SD} \\
\text { Range }\end{array}$ & $\begin{array}{l}0.063 \pm 0.027 \\
0.019-0.082\end{array}$ & $\begin{array}{l}0.0135 \pm 0.011 \\
0.003-0.026\end{array}$ & $8.899 \bullet$ & 0.000 & HS \\
\hline
\end{tabular}

P-value $\geq 0.05$ : Non significant (NS); P-value $<0.05$ : Significant (S); P-value $<0.01$ : highly significant (HS), *: Chi-square test, $\bullet:$ Independent t-test; $\ddagger$ : Mann Whitney test.

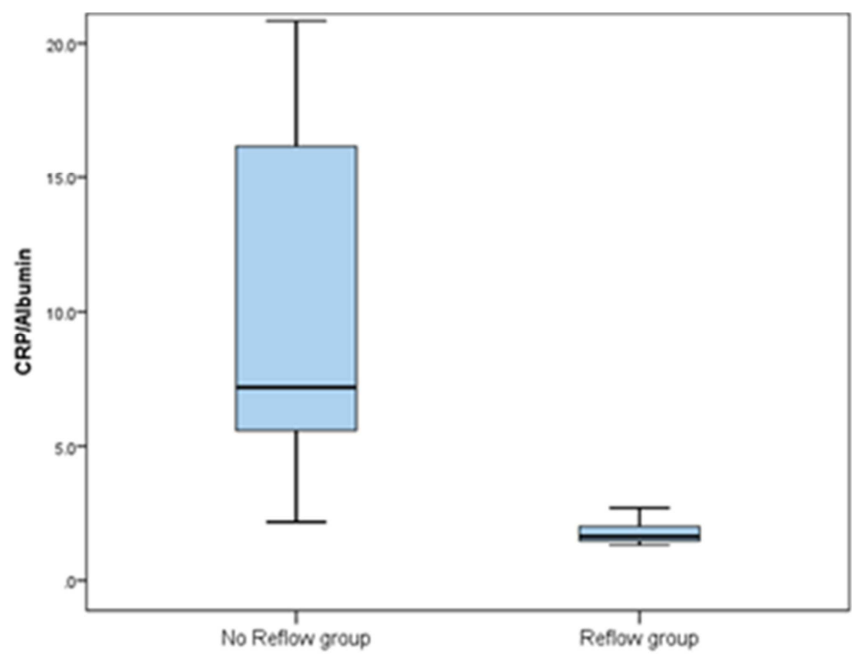

Figure 1. Comparison between the both groups regarding CRP/Albumin ratio (CAR). 
Logistic regression analysis:

Table 3, display the multivariate logistic regression analyses for the laboratory predictors of no-reflow in STEMI patients. Only the ratios CAR and MHR showed a significant predictive value with an odds ratio of 0.182 with a $p$ value $=0.000$ and 0.321 with a $p$ value $=0.002$ respectively.

Table 3. Multivariate logistic regression analysis for predictors of No-reflow in patients with STEMI.

\begin{tabular}{llllllll}
\hline & \multirow{2}{*}{ B } & \multirow{2}{*}{ S.E. } & \multirow{2}{*}{ Wald } & \multirow{2}{*}{ P-value } & \multirow{2}{*}{ Odds ratio (OR) } & \multicolumn{2}{l}{ 95\% C.I. for OR } \\
\cline { 7 - 8 } & & & & & Lower & Upper \\
\hline CRP & 0.074 & 1.020 & 0.005 & 0.943 & 1.076 & 0.146 & 7.946 \\
Albumin & 2.271 & 3.718 & 0.373 & 0.541 & 9.690 & 0.007 & 14169.139 \\
CRP/Albumin (CAR) & -1.705 & 0.436 & 15.301 & 0.000 & 0.182 & 0.077 & 0.427 \\
HDL & 0.191 & 0.112 & 2.914 & 0.088 & 1.211 & 0.972 & 1.508 \\
Monocytes & 0.032 & 0.026 & 1.824 & 0.103 & 1.392 & 0.063 & 1.320 \\
Monocytes/HDL (MHR) & -1.267 & 0.321 & 12.231 & 0.002 & 0.321 & 0.054 & 0.519 \\
\hline
\end{tabular}

Tables 4 and 5, show the cut-off values suggested for prediction of no-reflow in STEMI patients. The suggested cut-off values were as follows: $\mathrm{CRP} \geq 9$, albumin $<3.6$, monocytes $\geq 0.75$, $\mathrm{HDL}<36, \mathrm{CAR} \geq 3.26$ with area under curve (AUC) 0.974 and MHR $\geq 0.023$ with AUC 0.872 .

Table 4. Cut-off values for CRP, albumin and CRP / Albumin ratio.

\begin{tabular}{lllllll}
\hline & Cut off point & AUC & Sensitivity & Specificity & +PV & -PV \\
\hline CRP & $\geq 9$ & 0.966 & 79.49 & 97.44 & 96.9 & 82.6 \\
Albumin & $<3.6$ & 0.763 & 82.05 & 56.41 & 65.3 & 75.9 \\
CRP/Albumin (CAR) & $\geq 3.26$ & 0.974 & 92.31 & 89.74 & 90.0 & 92.1 \\
\hline
\end{tabular}

Table 5. Cut-off values for monocytes, HDL and monocytes / HDL ratio.

\begin{tabular}{lllllll}
\hline & Cut off point & AUC & Sensitivity & Specificity & +PV & -PV \\
\hline Monocyte & $\geq 0.75$ & 0.72 & 74.3 & 61.5 & 63.2 & 65.5 \\
HDL & $<36$ & 0.660 & 64.1 & 64.1 & 64.1 & 64.1 \\
Monocyte/HDL (MHR) & $\geq 0.023$ & 0.872 & 81.2 & 76.3 & 76.2 & 78.1 \\
\hline
\end{tabular}

\section{Discussion}

The goal of primary PCI in STEMI patients is the rapid restoration of coronary blood flow to the jeopardized myocardium and to improve overall survival. However, in up to $12-39 \%$ of patients, myocardial tissue perfusion does not occur despite the presence of normal epicardial flow $[11,12]$. This effect is known as the no-reflow phenomenon. In a recent work published by Hassan et al., 2018, they reported a $30 \%$ no-reflow in patients with PPCI in Assuit University [13] while Mazhar et al, 2016 [14] reported 25\% no-reflow in their patients' group. In this study we chose to examine patients who experienced no-reflow as a case control study.

No-reflow phenomenon strongly affects the outcome of PPCI and may limit the benefits of reopening of the infarctrelated artery. Early risk stratification in order to detect patients at high risk of no-reflow is very important for the anticipation, prevention, and treatment of this condition.

No-reflow has been clearly linked to increased mortality, poor outcome and increased 30 days readmission rates [15, 16]. There is plethora of published work examining various predictors of no-reflow [17-19]. To the best of our knowledge, this is the first published data on Egyptian patients. It adds to the work by Hassan et al., 2018 [13].

We didn't report any difference between the two groups with regards to gender or other risk factors (DM, HTN, smoking), this contrast the work of Celik et al., 2016 who found female gender to be an independent predictor of noreflow [17]. This can be attributed to delayed reperfusion time, as evidenced from Hassan et al. analysis of positive predictors [13]. Hence in the current study the control group was selected to match the study group as regard gender; these differences were not applicable for the current study.

In group A, (no-reflow) CRP was significantly higher reflecting ongoing inflammation associated with thrombosis. This is comparative to the data reported by Karabag et al. in 2018 [20]. Our data showed a lower Albumin level in patients who had no-reflow. In multivariate logistic regression analyses CAR showed a significant predictive value with an odds ratio of $0.182(\mathrm{p}$ value $=0.000)$.

We also examined monocyte/HDL ratio (MHR) as another marker reflecting acute inflammation, which proved to be a strong predictive factor with an odd ratio of 0.321 ( $\mathrm{p}$ value $=0.002$ ). This is similar to the data reported from Balta et al., 2016 [19].

\section{Conclusion}

No-reflow can be predicted by systemic inflammatory markers including CRP, monocytes, albumin, and HDL. Our results suggested that CAR and MHR on admission before PPCI though cheap, and easily measurable laboratory tools, have a significant predictive value with an odds ratio of 
0.182 with a $\mathrm{p}$ value $=0.000$ and 0.321 with a $\mathrm{p}$ value $=$ 0.002 respectively. They could help to risk stratify STEMI patients who might suffer from no-reflow phenomenon after PPCI.

\section{Limitations}

A larger randomized controlled trial is needed to verify the results achieved in the current study.

Myocardial blush grading was not evaluated in this study, which is important for assessment of tissue perfusion; and hence, contractility.

\section{References}

[1] Grines CL, Browne KF, Marco J, et al., (1993): A comparison of immediate angioplasty with thrombolytic therapy for acute myocardial infarction. The primary angioplasty in myocardial infarction study group. N Engl J Med; 328: 673-679.

[2] Michaels AD, Gibson CM, Barron HV. (2000): Microvascular dysfunction in acute myocardial infarction: focus on the roles of platelet and inflammatory media- tors in the no-reflow phenomenon. Am J Cardiol; 85: 50b-60b.

[3] Kloner RA, Ganote CE, Jennings RB. (1974): The "noreflow" phenomenon after temporary coronary occlusion in the dog. J Clin Invest; 54:1496-508.

[4] Thiele H, Schindler K, Friedenberger J, et al., (2008): Intracoronary compared with intravenous bolus abciximab application in patients with ST-elevation myocardial infarction undergoing primary percutaneous coronary intervention: the randomized Leipzig immediate percutaneous coronary intervention abciximab IV versus IC in ST-elevation myocardial infarction trial. Circulation; 118 (1): p. 49-57.

[5] Lim SY, Bae EH, Jeong MH, et al., (2004): Effect of combined intracoronary adenosine and nicorandil on noreflow phenomenon during percutaneous coronary intervention. Circulation, 2004. 68 (10): p. 928-932.

[6] Wilson RF, Laxson DD, Lesser, et al., (1989): Intense microvascular constriction after angioplasty of acute thrombotic coronary arterial lesions. Lancet; 1 (8642): p. 80711 .

[7] Amit KS, Harsh VS, Arun R, et al., (2015): C-reactive protein, inflammation and coronary heart disease, The Egyptian Heart Journal; 67, 89-97

[8] Mohammad M, and Omid F. (2013): Components of the Complete Blood Count as Risk Predictors for Coronary Heart Disease In-Depth Review and Update. Tex Heart Inst J; 40 (1): 17-29.

[9] Ibanez B, James S, Agewall S, et al., (2018): 2017 ESC Guidelines for the management of acute myocardial infarction in patients presenting with ST-segment elevation: The Task
Force for the management of acute myocardial infarction in patients presenting with ST-segment elevation of the European Society of Cardiology (ESC). Eur Heart J; 39: 119 177.

[10] The TIMI Study Group. (1984): The Thrombolysis in Myocardial Infarction (TIMI) trial: phase I findings. N Engl J Med; 33: 523-530

[11] Morishima I, Sone T, Okumura K, et al., (2000): Angiographic no-reflow phenomenon as a predictor of adverse long-term outcome in patients treated with percutaneous transluminal coronary angioplasty for first acute myocardial infarction. J Am Coll Cardiol; 36: 1202-1209.

[12] Tarantini G, Cacciavillani L, Corbetti F, et al., (2005): Duration of ischemia is a major determinant of transmurality and severe microvascular obstruction after primary angioplasty: a study performed with contrast-enhanced magnetic resonance. J Am Coll Cardiol; 46: 1229-1235.

[13] Hassan AKM, Mohamed HS, Mohamed AM, et al., (2018): Predictors of no-reflow in patients undergoing primary percutaneous coronary intervention. Thrombus aspiration was protective. Egyptian heart journal, Dec; 70 (4): 421-426.

[14] Mazhar J, Mashicharan M, Farshid A. (2016): Predictors and outcome of no-reflow post primary percutaneous coronary intervention for ST elevation myocardial infarction" Int J carotid Heart Vasc; 10:8-12.

[15] Ito H, Maruyama A, Iwakura K, et al., (1996): Clinical implications of the 'no reflow' phenomenon. A predictor of complications and left ventricular remodeling in reperfused anterior wall myocardial infarction. Circulation; 93 (2): p. 223-8.

[16] Resnic FS, Wainstein M, Lee MK, et al., (2003): No-reflow is an independent predictor of death and myocardial infarction after percutaneous coronary intervention. Am Heart J; 145 (1): p. $42-6$.

[17] Celik T, Balta S, Ozturk C, et al., (2016): Predictors of NoReflow Phenomenon in Young Patients With Acute STSegment Elevation Myocardial Infarction Undergoing Primary Percutaneous Coronary Intervention. Angiology; 67 (7):683-9.

[18] Jomaa W, Jnifene Z, Chamtouri I, et al., (2019): Predictors of No-Reflow Phenomenon in Tunisian Patients Undergoing Primary Percutaneous Coronary Intervention for St-Elevation Myocardial Infarction. JACC: Volume 12, Issue 4 Supplement, February.

[19] Balta S, Celik T, Ozturk C, et al., (2016): The relation between monocyte to HDL ratio and no-reflow phenomenon in the patients with acute ST-segment elevation myocardial infarction" Am J Emerg Med. Aug; 34 (8):1542-7.

[20] Karabağ Y, Çağdaş M, Rencuzogullari I, et al., (2018): Usefulness of The C - Reactive Protein/Albumin Ratio for Predicting No-Reflow in ST-elevation myocardial infarction treated with primary percutaneous coronary intervention. Eur J Clin Invest; 48: e12928. 